\title{
Comparative sensitivity of different serological tests for detecting chlamydial antibodies in perihepatitis
}

\author{
MIRJA PUOLAKKAINEN, PEKKA SAIKKU, MAIJA LEINONEN, \\ MARJATTA NURMINEN, PERTTI VÄÄNÄNEN, P HELENA MÄKELÄ
}

From the Department of Virology, University of Helsinki, and the National Public Health Institute, Helsinki, Finland

SUMMARY The value of several serological tests was assessed by studying sera from 30 women with clinical findings of perihepatitis and a high chlamydial antibody titre in the indirect immunofluorescence antibody test (IFAT). The other tests included the complement fixation test and enzyme immunoassays in which the antigen comprised either partially purified particles (EIA kit) or purified major outer membrane protein (MOMP EIA) of Chlamydia trachomatis $\mathrm{L}_{2}$ or lipopolysaccharide isolated from an Re mutant of Salmonella (Re LPS EIA). High IgG titres were noted in most (88-96\%) of the patients by MOMP EIA and EIA kit, and in fewer patients $(50 \%)$ by Re LPS EIA or complement fixation test. Seroconversion was found in 11-44\% of the patients for IgG and in $28-36 \%$ for IgM; high IgG titre was thus the best diagnostic indicator for each test.

The enzyme immunoassay tests have the advantage of being automated either with partially purified corpuscular or purified MOMP antigen and would allow a sensitive easy screening for chlamydial aetiology of women with pain of the right upper quadrant.

Perihepatitis is a localised form of peritonitis often found as a complication of pelvic inflammatory disease. Chlamydia trachomatis seems to be the most common causative agent.' Chlamydial perihepatitis may be much more common than has previously been supposed, and it may account for a considerable part of acute cholecystitis in young women. ${ }^{23}$ Serology seems to be a promising aetiological diagnostic method as patients with chlamydial perihepatitis have unusually high antichlamydial IgG titres. ${ }^{14}$ We reported the use of two purified antigens in enzyme immunoassay for chlamydial serology. ${ }^{5}$ Here we present our experience with enzyme immunoassay using these purified antigens and compare them with the indirect immunofluorescent antibody test, the complement fixation test, and a commercially available EIA kit using crude antigen for the serological diagnosis of chlamydial perihepatitis.

\section{Patients and methods}

Thirty patients with high antichlamydial IgG titres in IFAT $(\geqslant 1 / 128)^{67}$ were identified among women

Accepted for publication 12 April 1985 whose sera were sent to the department of virology between 1978 and 1983 because of suspected chlamydial perihepatitis. They all had the basic clinical criteria of abdominal pain of acute onset of the upper right side and tenderness in the right subcostal area, often associated with actual or premonitory symptoms of genital infection.

Irradiated or McCoy cells treated with cycloheximide were used for chlamydial isolation, and the inclusions were detected by staining with iodine. A complement fixation test was performed using a commercial group antigen (Ornithosis Antigen for CFT, Behringwerke AG, Marburg, West Germany). Indirect immunofluorescence antibody test (IFAT) was carried out using inclusions and reticulate bodies of $C$ trachomatis $\mathrm{L}_{2}$ as antigens, and fluoresceine isothiocyanate conjugated antihuman IgG (Wellcome Research Laboratories, Beckenham, England) and IgM and IgA (Kallestad, Chaska, United States).

Enzyme immunoassays were performed with two purified and one crude antigen. Major outer membrane protein (MOMP) was purified from $C$ trachomatis $\mathrm{L}_{2}$ elementary bodies ${ }^{8}$ and lipopolysaccharide (Re LPS) from an Re mutant mR595 of Salmonella minnesota, shown to cross react with the 
genus specific chlamydial glycolipid." In MOMP EIA and Re LPS EIA the patient sera were tested in three tenfold dilutions, and the class specific antibodies detected with alkaline phosphatase conjugated swine antihuman $\operatorname{IgG}, \operatorname{IgA}$, and $\operatorname{IgM}$ reagents (Orion Diagnostica, Helsinki, Finland). ${ }^{5}$ The $95 \%$ confidence limits were determined from titrations of 90 sera from healthy blood donors from the Finnish Red Cross Blood Transfusion Service. The crude antigen consisted of partially purified particles of $C$ trachomatis $\mathrm{L}$, in a commercially available EIA kit (Chlamydial antibody EIA, Orion Diagnostica, Helsinki, Finland); in this assay the sera were tested in a single dilution of $1: 100$, and only anti-IgG conjugate was used. The antibody titre was calculated from the optical density value by comparison with standard sera of known IFAT titres according to Puolakkainen et al. ${ }^{5}$

For established tests (complement fixation test and IFAT) the criteria for clinically significant IgG titres were taken from studies; $\geqslant 64$ for complement fixation test ${ }^{10}$ and $\geqslant 128$ for IFAT. ${ }^{6}$ The EIA kit is standardised against IFAT, and it seems reasonable to apply the same limit bar one exception. ${ }^{5}$ On the basis of similar arguments applied to the clinical materials tested we suggested the titre value of $>700$ for the corresponding limit for IgG enzyme immunoassay with the purified antigens.

All the sera were tested by Rapi Tex-RF (Latex RF Reagent, Behringwerke AG, Marburg, West Germany) for the presence of rheumatoid factors.

\section{Results}

\section{CLINICAL FINDINGS}

All the women had typical clinical symptoms of perihepatitis - that is, pain of the right upper quadrant, considerable tenderness in the right subcostal area, and often actual or premonitory signs of genital infection, although this was often mild. Ten women had recently undergone either induced (7/ $10)$ or spontaneous $(3 / 10)$ abortion. Duration of the symptoms before seeing a doctor varied from one day to 1.5 months (mean nine days). Nine of these women used an intrauterine device and five took oral contraceptives. Two patients had experienced chlamydial perihepatitis two years previously. Ninety per cent of these women had a raised rate of erythrocyte sedimentation ( $>15 \mathrm{~mm}$ in 1 hour), but only $3 / 21$ had a white blood cell count of $>12 \times$ $10^{\varphi} / 1$ and none had increased liver transaminase activity.

Six patients had their gall bladder examined by radiography; the finding was normal in all of them. Ultrasonographic examination of the biliary tract was performed in 18 cases. One patient had gall stones and she subsequently underwent surgery. At operation adhesions between the surface of the liver and the anterior abdominal wall were found. One patient underwent laparoscopy because of unexplained upper abdominal pain (again adhesions were noticed). Three patients were suspected of having acute appendicitis and they underwent prophylactic appendicectomy. Three patients underwent gastroscopy and one rectoscopy, but the findings were normal. All but one received antibiotics effective against $C$ trachomatis.

\section{RESULTS OF MICROBIAL CULTURES}

Cervical culture for Neisseria gonorrhoeae was positive in one of 19 patients tested. $C$ trachomatis was found in three of 14 cervical specimens. One attempt to isolate $C$ trachomatis from a swab from the surface of the liver obtained during laparoscopy was unsuccessful; the cervical swab of this patient, however, yielded $C$ trachomatis. Clostridium perfringens was grown from peritoneal exudate obtained during appendicectomy of one patient.

\section{SEROLOGICAL TESTS}

Fig. 1 shows antichlamydial IgG and complement fixation test titres. By definition, all the patients had clinically significant IgG titres in I/RB IFAT, with a geometric mean titre of 1024 . The titres obtained by the commercial EIA kit were slightly lower (geometric mean titre 600 ), and $96 \%$ of the patients had clinically significant titres. In the complement fixation test the titres were lower (geometric mean titre 38); $50 \%$ had significant titres and $17 \%$ remained negative. Remarkably high IgG titres were measured by MOMP EIA (geometric mean titre 2933), but by Re-LPS-EIA the titres were only moderately raised (geometric mean titre about the suggested titre limit of clinical significance). One patient remained negative for both tests.

Fig. 2 shows the IgA and IgM class antibody titres. IgA class antibodies were detected in 54-93\% of the patients, but only by MOMP-EIA were the titres clearly higher (geometric mean titre 780) than in the normal population (upper $95 \%$ confidence limit 100). One patient had rheumatoid factors in her sera, and thus her IgM results are omitted (figures in parentheses). Only $28-36 \%$ of the patients had measurable levels of IgM antibodies, and the titres were quite low, the geometric mean titre being close to the upper $95 \%$ confidence limit in the normal material. Sequential samples (mean interval 31 days) were available from nine patients, six of whom showed seroconversion: one patient by IFAT, two by complement fixation test or the EIA-kit, three by Re LPS EIA and four by MOMP EIA (table). The table also shows that a single 


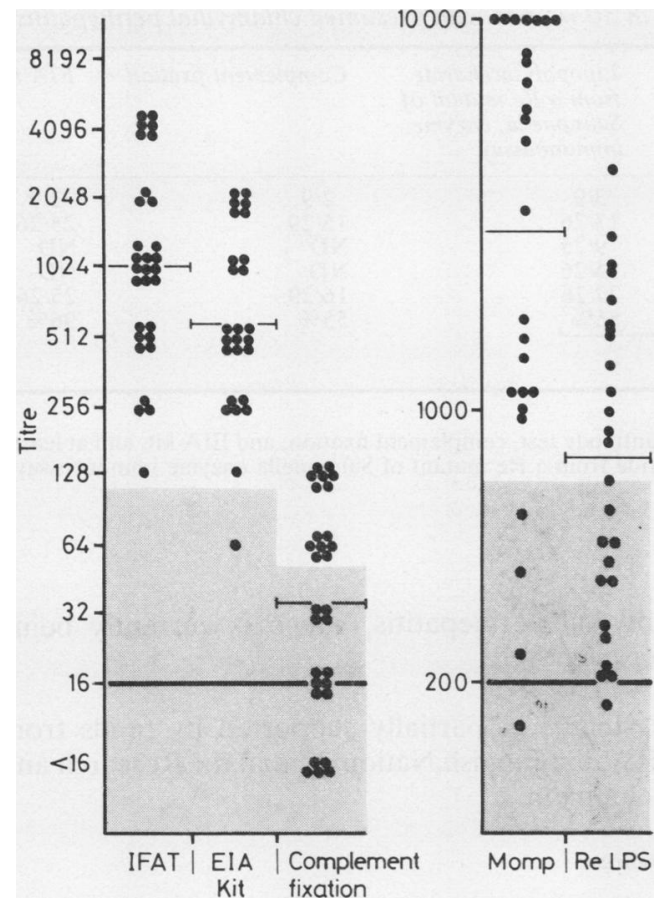

Fig. 1 Distribution of antichlamydial $\operatorname{Ig} G$ and $C F$ titres in 30 patients with presumed chlamydial perihepatitis (identified by IFAT) with limits of a positive reading* and geometric mean titres indicated $\dagger$.

significantly high IgG value (in either serum sample) obtained by MOMP EIA or by the EIA kit (crude antigen) gave a presumptive diagnosis in $88-96 \%$ of the cases. The $\operatorname{Re}$ LPS EIA and complement fixation test gave distinctly fewer diagnoses. When the presence of IgA or IgM antibodies (present in either serum sample, mostly in the first one), or both, was also used as a criterion six more diagnoses were obtained by Re LPS EIA, but none by MOMP EIA.

\section{Discussion}

The unexpected incidence of perihepatitis shown in some recent studies ${ }^{3}$ illustrates the difficulties in the

\begin{abstract}
*The lowest dilution tested for indirect immunofluorescence antibody test and complement fixation test and the upper $95 \%$ confidence limit of normal sera for enzyme immunoassays, using chlamydial major outer membrane protein, and lipopolysaccharide from an $\operatorname{Re}$ mutant of Salmonella
\end{abstract}

†The titres above the grey area are considered clinically significant. ${ }^{6} 10$
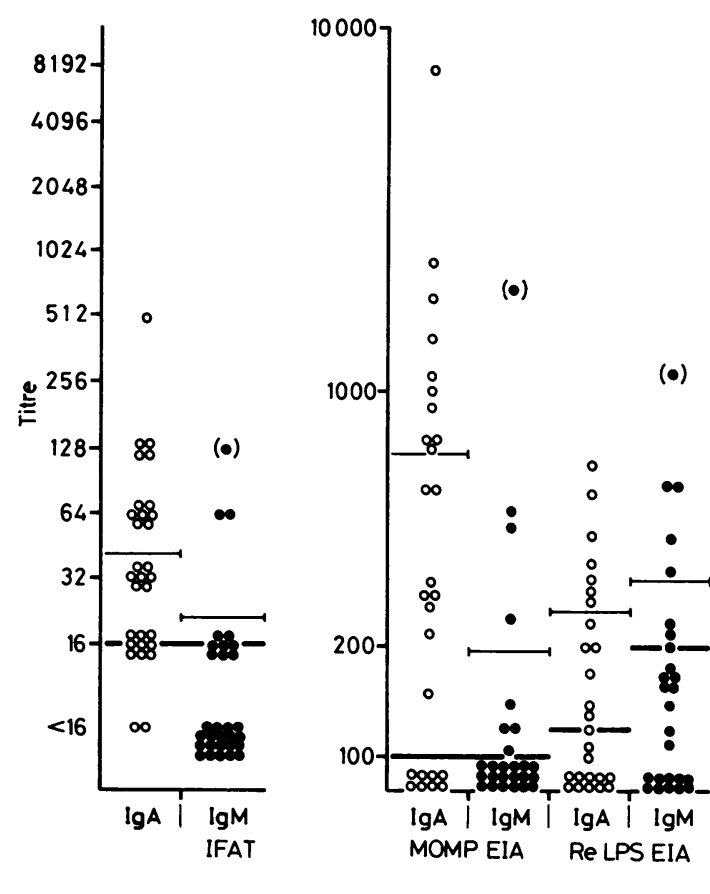

Fig. 2 Antichlamydial $\operatorname{IgA}(\mathrm{O})$ and $\operatorname{IgM}(0)$ titres in 30 patients with presumed chlamydial perihepatitis with limits for a positive reading (-) and geometric mean titres indicated.

diagnosis of the syndrome. Our study also supports this, with its many initially misdiagnosed patients. Although definitive diagnosis requires laparoscopy or laparotomy, non-invasive methods are of primary importance in clinical practice. Wang et al first pointed out the exceptionally high antichlamydial antibody titres in patients with perihepatitis.' Chlamydias are effective immunogens, and the large inflamed peritoneal surfaces seem to provide a strong antigenic stimulus during the disease: the present data on patients with perihepatitis show a mean IFAT titre that was eight times higher than the generally accepted limit for high, a clinically significant value. ${ }^{67}$ Even the relatively insensitive complement fixation test showed diagnostic titres in half of the cases.

Our results also show that the complement fixation test, which is still the only test available in many laboratories, is not satisfactory, and more sensitive tests are required for the diagnosis of chlamydial perihepatitis. IFAT is generally considered to be the method of reference because of its sensitivity and specificity. ${ }^{6}$ The new enzyme immunoassays proved, in both respects, equal to the IFAT 
Table Presumptive diagnostic value of individual serological tests in 30 women with presumed chlamydial perihepatitis

\begin{tabular}{|c|c|c|c|c|c|}
\hline Criteria for diagnosis & $\begin{array}{l}\text { Indirect } \\
\text { immunofuorescence } \\
\text { antibody test }\end{array}$ & $\begin{array}{l}\text { Major outer } \\
\text { membrane protein } \\
\text { enzyme immunoassay }\end{array}$ & $\begin{array}{l}\text { Lipopolysaccharide } \\
\text { from a Re mutant of } \\
\text { Salmonella, enzyme } \\
\text { immunoassay }\end{array}$ & Complement fixation & EIA kit \\
\hline $\begin{array}{l}\text { Titre rise or fall in IgG* } \\
\text { High IgG titre } \dagger \\
\text { IgM present\$ } \\
\text { IgA present\$ } \\
\text { Serological diagnosis } \\
\text { obtained (overlapping } \\
\text { eliminated) }\end{array}$ & $\begin{array}{l}1 / 9 \\
30 / 30 \dagger \\
11 / 25 \\
28 / 30 \\
30 / 30 \\
100 \% \ddagger\end{array}$ & $\begin{array}{r}25 / 26 \\
96 \%\end{array}$ & $\begin{array}{l}3 / 9 \\
13 / 26 \\
9 / 25 \\
14 / 26 \\
22 / 26 \\
85 \% \\
\end{array}$ & $\begin{array}{l}2 / 9 \\
15 / 29 \\
\mathrm{ND}^{\prime /} \\
\mathrm{ND} \\
16 / 29 \\
55 \%\end{array}$ & $\begin{array}{l}2 / 9 \\
25 / 26 \\
\text { ND } \\
\text { ND } \\
25 / 26 \\
96 \%\end{array}$ \\
\hline
\end{tabular}

All diagnosis confirmed by indirect immunofluorescence antibody test.

${ }^{*}$ Defined as at least a fourfold titre change in indirect immunofluorescence antibody test, complement fixation, and EIA kit, and at least a twofold titre change in major outer membrane protein and lipopolysaccharide from a Re mutant of Salmonella enzyme immunoassay. tCriteria for high IgG titre, see text.

$\ddagger$ By definition.

\$Above the upper $95 \%$ confidence limit of normal material.

"Not determined.

and definitely superior to the complement fixation test. The purified antigens (the protein MOMP and the glycolipid Re-LPS), were more sensitive than the crude chlamydial antigen in showing seroconversion and allowed the measurement of IgM and IgA responses (these cannot be performed with the EIA kit). The sensitivities of the purified antigens are, however, not especially useful in diagnosing perihepatitis, which is a late complication of chlamydial cervicitis; the initial $\operatorname{IgM}$ and IgA responses may have already declined while the IgG titre still remains high. In our study an IgM response was recorded in $28-36 \%$ of cases and IgG seroconversion in $11-44 \%$, whereas a high IgG titre was present in $88-96 \%$ of cases.

The value of isolating $C$ trachomatis from the cervix is questionable in perihepatitis as most patients have negative cultures. ${ }^{2}$ This was evident in our material. Moreover, the prevalence of chlamydial carriers among women is considerable (5\% in Fin-

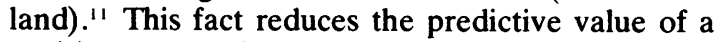
positive result from a culture test for cervical Chlamydia.

In conclusion, an exceptionally high antichlamydial IgG titre seems the best laboratory indication of chlamydial perihepatitis. The immunofluorescence test and enzyme immunoassay, using either a crude chlamydial antigen or the purified protein antigen, were found to be almost equally sensitive. The chlamydial group antigen used in complement fixation test or enzyme immunoassay (Re LPS) proved less sensitive in this condition. The screening of antichlamydial IgG titres with enzyme immunoassay, even if non-purified chlamydial antigens are used, is quick and easy. It could therefore be used as an alternative routine test to indirect immunofluorescence antibody test in all women presenting with abdominal pain in the right upper quadrant, and could be of essential help in recognising chlamydial perihepatitis, which is currently being underdiagnosed.

This study was partially supported by funds from SITRA, the Finnish National Fund for Research and Development.

\section{References}

${ }^{1}$ Wang SP, Eschenbach DA, Holmes KK, Wager G, Grayston JT. Chlamydia trachomatis infection in Fitz-Hugh-Curtis syndrome. Am J Obstet Gynecol 1980;138:1034-8.

${ }^{2}$ Darougar S, Forsey T, Wood JJ, Bolton JP, Allan A. Chlamydia and the Curtis-Fitz-Hugh syndrome. $\mathrm{Br} J$ Vener Dis 1981;57:391-4.

${ }^{3}$ Clair J, Kurtz JB. Chlamydia trachomatis and upper abdominal pain. Lancet 1983; i: 1044-5.

4 Paavonen J, Saikku P, von Knorring J, Aho K, Wang SP. Association of infection with Chlamydia trachomatis with Fitz-Hugh-Curtis syndrome. J Infect Dis 1981;144:176.

${ }^{5}$ Puolakkainen M, Saikku P, Leinonen M, Nurminen M, Väänänen $\mathrm{P}$, Mäkelä $\mathrm{PH}$. Chlamydial pneumonitis and its serodiagnosis in infants. $J$ Infect Dis 1984; 149:598-604.

- Darougar S, Treharne JD. Chlamydial infections: Laboratory aspects. In RW Harris ed. Recent advances in sexually transmitted diseases, Vol. 2. London: Churchill Livingstone, 1981;141.

' Saikku P, Paavonen J. Single-antigen immunofluorescence test for chlamydial antibodies. J Clin Microbiol 1978;8:119-22.

${ }^{8}$ Nurminen M, Lounatmaa K, Leinonen M, Wahlström E. The effect of mercaptoethanol on the solubilization of the 39.5 $\mathrm{kDa}$ major outer membrane protein of elementary bodies of Chlamydia trachomatis and purification of the protein. FEMS Microbiol Lett 1984;24:185-91.

${ }^{9}$ Nurminen M, Leinonen M, Saikku P, Mäkelä PH. The genusspecific antigen of chlamydia: resemblance to the lipopolysaccharide of enteric bacteria. Science 1983;220:1279-81.

${ }^{10}$ Schachter J. Chlamydiae. In: Rose NR, Friedman H, eds. Manual of Clinical Immunology. 2nd ed. Washington DC: American Society for Microbiology, 1980;700-6.

"Paavonen J, Saikku P, Vesterinen E, Meyer B, Vartiainen E, Saksela E. Genital chlamydial infections in patients attending a gynaecological outpatient clinic. $B r J$ Vener Dis 1978;54:257-61.

Requests for reprints to: Dr Mirja Puolakkainen, Department of Virology, University of Helsinki, Haartmaninkatu 3, SF-00290 Helsinki 29, Finland. 